\title{
O CONSÓRCIO PÚBLICO PARA DESENVOLVIMENTO DO ALTO PARAOPEBA (CODAP/MG) E OS REFLEXOS DA GESTÃO PÚBLICA INTEGRADA
}

\author{
THE CONSÓRCIO PÚBLICO PARA DESENVOLVIMENTO DO \\ ALTO PARAOPEBA (CODAP/MG) AND REFLECTIONS OF \\ INTEGRATED PUBLIC MANAGEMENT
}

\author{
Hilton Manoel Dias Ribeiro \\ Universidade Federal de Juiz de Fora - MG - Brasil \\ Dalva Maria Righi Dotto \\ Universidade Federal de Santa Maria - RS - Brasil
}

\begin{abstract}
Resumo: O objetivo deste estudo foi analisar os efeitos da formação de consórcio público sob o ponto de vista do governo local, tendo como base empírica o Consórcio Público para Desenvolvimento do Alto Paraopeba - CODAP. A base teórica contempla uma discussão sobre instituições e consórcios públicos, reforçando a importância que a dimensão institucional, no que tange à atuação do Estado, tem para o desenvolvimento de regiões. A metodologia empregada foi o estudo de caso. Os resultados sinalizaram mudanças nos indicadores ao longo do tempo e também uma relação positiva entre a instalação do CODAP e os avanços na gestão pública integrada, percebendo que as questões anteriormente excluídas das pautas das políticas municipais entraram no eixo dos programas para o desenvolvimento da região, incluindo a formulação de um planejamento conjunto que tem gerado resultados coletivos positivos.
\end{abstract}

Palavras-chave: Instituições. Consórcio Público. CODAP. Desenvolvimento de regiões.

Abstract: The focus of this paper was to analyze the effects of the formation of public consortiums, as seen by the local government, basing on the case study of the Consórcio Público para Desenvolvimento do Alto Paraopeba - CODAP. The theory includes a discussion about public institutions and consortia, reinforcing the importance that the institutional dimension, while in the range of action of the State, has to the development of the regions. The methodology used was the exploratory research. The results exposed changes in indicators over time and a positive relationship between the installation of CODAP and advances in integrated public management, perceiving that the once excluded questions from the municipal political agenda have entered in the regional development programs axis, including the formation of an conjunct planning that has been producing positive collective results.

Keywords: Institutions. Public Consortia. CODAP. Regional development.

\section{Introdução}

As discussões a respeito do crescimento e do desenvolvimento, seja de um município, de uma região ou de um país, estão quase sempre relacionadas a fatores econômicos, tecnológicos e de caráter mais quantitativo. Contudo, apesar da relevância desses fatores, também se deve incluir nos estudos sobre desenvolvimento os aspectos relacionados às instituições formais e informais que se firmaram ao longo do tempo em determinada região e que também são responsáveis pelo seu desenvolvimento. 
O histórico e a base institucional condicionaram fortemente o início e os desdobramentos dos processos de desenvolvimento das regiões. Nesse sentido, o presente estudo pretende identificar como uma mudança institucional, nesse caso a instalação de um consórcio público, pode afetar o desenvolvimento, considerando as diversas dimensões. Especificamente, têm-se como objetivos o levantamento de informações sobre instituições, desenvolvimento e consórcios públicos; e a verificação de como a instalação do CODAP está relacionada a uma melhoria da gestão pública integrada, sob a ótica das Prefeituras.

A região do Alto Paraopeba está localizada no Estado de Minas Gerais, em posição geográfica central, e é composta por 23 municípios. O presente estudo concentra-se em uma parte específica, formada por sete municípios: Congonhas, Conselheiro Lafaiete, Jeceaba, Ouro Branco, São Brás do Suaçuí, Belo Vale e Entre Rios de Minas, pertencentes ao primeiro consórcio público de Minas Gerais, que recebe o nome de Consórcio Público para Desenvolvimento do Alto Paraopeba CODAP - (Figura 1).

As atividades econômicas principais dessa região são a agropecuária e a extração mineral. A região é representativa dentro do Estado no que se refere à produção e ao fornecimento de produtos primários e semielaborados para grandes centros, como Belo Horizonte. Destaca-se a produção de bananas, laranjas, batata, mandioca, arroz, tomate, cana-de-açúcar, café, feijão, milho. Além disso, também são significativas as atividades de pecuária de corte e leiteira.

Figura 1. Região geográfica dos municípios pertencentes ao CODAP

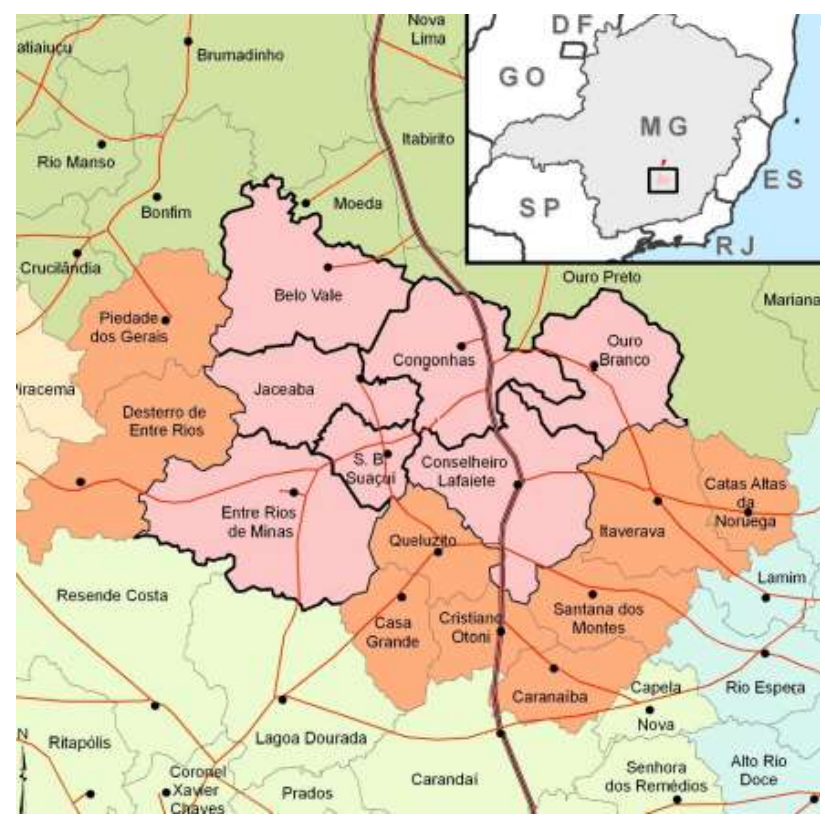

\section{LEGENDA}

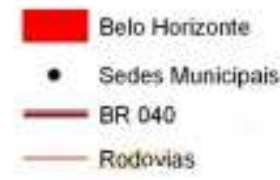

\section{REGIĀO DE REFERÊNCIA}
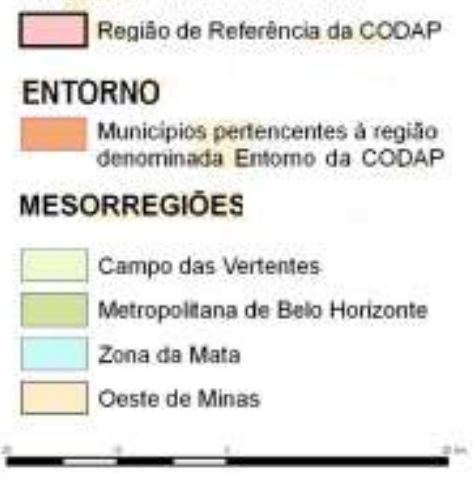

Fonte - Ruiz e Barbieri (2011)

O CODAP foi oficialmente criado em 2006, sob a nova lei dos consórcios públicos. Desse grupo, cinco estão participando desde então, enquanto que os 
municípios de Belo Vale e Entre Rios de Minas estão participando desde 2009. Esse consórcio tem procurado cobrir programas em que o caráter coletivo é predominante, como compras coletivas, planejamentos regionais e captação de recursos. Os Prefeitos têm participado das assembleias e reuniões que a Secretaria Executiva do CODAP tem planejado. Sendo assim, essa Secretaria é responsável pela gestão do consórcio, principalmente da manutenção desse ambiente institucional favorável ao trabalho colaborativo.

A discussão sobre o planejamento regional do Alto Paraopeba pode ser vista em Mello, Ferreira e Leite (2010). Nessa disussão, os autores citam o CODAP "como um sistema urbano com intensos e variados fluxos de pessoas e bens, ou seja, ir além da dimensão municipal". Vale destacar que se trata de um avanço importante no que tange à articulação entre atores locais e não locais, setor público e privado e diferentes esferas do governo. Os autores enfatizam ainda que a experiência do associativismo municipal, sob a forma de Consórcio, apresenta-se como um arranjo de gestão pública no qual se garante maior eficiência e abrangência das ações. Esse associativismo ameniza problemas relacionados ao municipalismo que decorre da falta de recursos por conta da pequena escala das estruturas municipais, bem como facilita na coordenação de um planejamento regional em detrimento do local.

\section{Intituições e desenvolvimento}

Cabe iniciar este tópico com o seguinte questionamento: Qual o papel efetivo que o conjunto de instituições, formais e informais, desempenha no processo de desenvolvimento de regiões? Este tópico dá ênfase a dois pontos importantes: a discussão crítica a respeito de desenvolvimento e como este desenvolvimento se relaciona com outras dimensões, que não só a econômica.

Sobre o primeiro, Esteva (2000) argumenta que depois da Segunda Grande Guerra, ficou claro que as ações e políticas dos países do Sul giravam em torno do desenvolvimento. Esse conceito de desenvolvimento está altamente relacionado com as palavras com as quais foi criado: crescimento, evolução, maturação.

Sobre o segundo ponto, contando com as ideias de Peyrefitte (2000), defende-se que a confiança desponta como a quinta essência das condutas culturais, religiosas, sociais e políticas que exercem influência decisiva no desenvolvimento. Para o autor, alguns traços permitem identificar as sociedades não desenvolvidas: imobilidade social; hostilidade à inovação; fragmentação social; intolerância; saúde precária; altas taxas de natalidade; penúria; e falta de segurança.

Soares (2009) enfatiza que os fatores imateriais como religião, preconceitos, superstições, atitudes perante as autoridades, tabus, comportamentos no tocante à mudança moral individual e do grupo, valores e educação sempre foram considerados insignificantes, ao contrário de fatores como matéria-prima, capitais, mão de obra, relações de produção, investimentos, trocas, distribuição, índices de crescimento etc. Complementarmente Peyrefitte (2000) afirma que há grande 
dificuldade em reconhecer que a forma de pensar, ou o comportamento coletivo, possa ter efeitos materiais. O discurso do autor destaca definitivamente o papel que o ambiente social exerce sobre o desenvolvimento. Esse ambiente denso de confiança pode ser interpretado como um conjunto de redes de interação, no qual nada se manifesta de maneira absolutamente independente.

Esse ambiente social pode ser visto pela análise de redes sociais, que surgiu pela necessidade de considerar processos sociais (redes de instituições e pessoas) concretos que colaborassem com o entendimento do desenvolvimento diferenciado de certas regiões, mesmo que estas tenham passado pelas mesmas transformações estruturais econômicas, sociais ou políticas. As unidades efetivas do desenvolvimento não são nem indivíduos nem famílias, mas sim conjuntos de pessoas ligadas por relações de amizade, de conhecimento, de parentesco, de trabalho e, sobretudo, de cooperação (SOARES, 2009).

Outro autor de destaque é North (1990), que discute a chave do desenvolvimento não apenas como vantagens naturais ou acumulação de capital e sim como a forma que as instituições estão enraizadas em determinada localidade. Há sociedades que investiram na democratização dos recursos produtivos, no estímulo à inovação e na valorização do conhecimento e, por outro lado, temos aquelas sociedades que criaram monopólios e que não investiram em educação, o que pode ter sido determinante para a criação de condições gerais mais improdutivas neste último.

Entender o desenvolvimento contempla uma série de fatores como os econômicos, os sociais, os ambientais e os institucionais. Autores como Granoveter (1985), Storper (1997), Schmitz (1997) e Amin (1998) são algumas das contribuições sobre as novas abordagens da teoria do desenvolvimento. $O$ primeiro deles, em sua publicação de título Economic Action and Social Structure: the problem of embeddedness, preocupa-se com a imersão social, nesse caso para uma moderna sociedade industrial, em contraposição à visão neoclássica de desenvolvimento. "I have argued that social relation, rather than institutional arrangements or generalized morality, are mainly responible for the production of trust in economic life" (GRANOVETER, 1985, p.491).

Para STORPER (1997, p.29), em "Regional Economies as Relational Assets", o paradigma ortodoxo permanece fundamentalmente preocupado com preços e quantidade, enquanto o paradigma heterodoxo quebra o problema do desenvolvimento econômico das regiões em uma série de domínios empíricos e teóricos, em tentativas de construir uma explicação de outras dimensões; essa abordagem heterodoxa envolve a tríade: tecnologia - organizações - territórios. "Rules, institutions, and action frameworks have always been important, of course, as institutionalist social scientists have shown".

Schmitz (1997) trata de clusters, economias externas e eficiência coletiva. Importante destacar neste trabalho que os efeitos cooperativos foram definitivamente mais comuns quando se compara, por exemplo, o cluster calçadista italiano e o mexicano. Dessa forma, economias externas são importantes 
para o crescimento, mas não são suficientes para superar grandes mudanças nos mercados de produtos e fatores, que requerem ação conjunta.

AMIN (1998), em "An Institutionalist Perspective on Regional Economic Development", não teve o objetivo de discutir em profundidade o pensamento institucionalista, mas oferece um relato estilizado de algumas correntes de pensamento que contribuem para explicar a economia como processo instituído e uma atividade socialmente enraizada. Esse autor vai além das visões neoclássicas que enfatizam economias de escala, aglomeração e custos de transação, sendo imersão social, cultura e a promoção de arranjos institucionais mais eficientes e determinantes para a dinâmica de desenvolvimento regional.

Torna-se claro que as políticas de Estado voltadas para o desenvolvimento devem fomentar a construção e a promoção de quadros institucionais que garantam a aproximação de capacidades e habilidades, alimentando redes sociais em meio aos conflitos de interesses, com vistas à estruturação de ambientes institucionais que promovam o desenvolvimento das regiões. É sob essa abordagem que se apresenta a importância dos consórcios públicos, incorporados recentemente à legislação brasileira, e que, como instrumentos de gestão pública, são capazes de criar um ambiente cooperativo ou, pelo menos, de fornecer instrumentos para tanto. A construção de consórcios públicos pode representar um avanço em termos de políticas públicas ancoradas em ambientes institucionais favoráveis ao desenvolvimento de regiões. A evolução desse instrumento é um amadurecimento da lógica institucional em que outras dimensões entram no cerne do debate sobre desenvolvimento.

\section{Consórcio público como estratégia regional}

Desde a Constituição de 1988, a construção de redes de municípios, chamadas de Consórcios Públicos, tem tomado força no território brasileiro. São inúmeras formas de consórcios, para fins variados, mas com a lógica colaborativa como essência desse tipo de instrumento de política pública. Contudo, a legislação brasileira foi ganhando novos contornos e, desde 2006, os consórcios ganharam outras formas, passando também a se constituir como Pessoa Jurídica de Direito Público. No modelo antigo, o Consórcio Intermunicipal previa acordos muito semelhantes aos convênios, sendo livremente firmado entre as partes, sem imposições ou restrições ditadas por legislação especifica (exceto SUS - Lei $\mathrm{n}^{\circ}$ 8.080/90), constituídos por Entes da mesma esfera de Governo e considerados Pessoa Jurídica de Direito Privado. Os Consórcios Públicos, incluídos neste novo modelo, necessitam de acordos claramente diferentes dos convênios, sendo firmados entre as partes, segundo legislação federal específica (Lei $n^{\circ}$ 11.107), constituídos por Entes de mesmas ou diferentes esferas de Governo e dotados de personalidade jurídica denominada Associação Pública de Direito Público e natureza autárquica. 
Em Minas Gerais, o primeiro Consórcio Público, sob o regime da Lei Federal no 11.107, é o Consórcio Público para Desenvolvimento do Alto Paraopeba CODAP.

Segundo informações da Secretaria de Desenvolvimento e Planejamento Regional - SEDRU (2011), entre as principais vantagens da formação de consórcios para a gestão pública, citam-se os ganhos crescentes de escala (quanto maior a população atendida, menores são os custos de manutenção da estrutura que presta esses serviços, pois essa deixa de ser subutilizada); a maior facilidade encontrada na captação de recursos: uma vez que os consórcios representam sempre grupos de municípios, esses tendem a ser vistos como prioridades - em relação aos pedidos feitos por municípios isolados - pelas fontes de recursos. 0 consorciamento, nesse sentido, representa o equacionamento de problemas em escala regional, algo preferível, sobretudo no caso de problemas cujas consequências dificilmente se limitam a atingir apenas um município; e a ampliação de receitas: no caso de consórcios intermunicipais de gestão de resíduos sólidos, há possibilidade de obtenção de recursos a partir dos produtos resultantes da reciclagem e da compostagem, assim como do repasse de ICMS ecológico (Lei Estadual 13.803/00).

Além disso, se pode considerar também outros pontos a favor desse mecanismo de gestão de territórios, como, por exemplo, a identidade de atividades e problemas, com a superação do limite das bandeiras partidárias; implementação de mecanismos de articulação e colaboração mútua; formulação e execução de políticas regionais com redução de custos operacionais; fortalecimento político da região; compras coletivas; fiscalização tributária conjunta etc.

A contribuição de Laczynsky (2010) sobre consórcios públicos compreende como objetivo inicial a redução da pobreza nas periferias das áreas metropolitanas do Brasil, com ênfase para o desenvolvimento 'de baixo para cima' de mecanismos interjurisdicionais que lidem com assuntos relativos a assentamentos precários informais e exclusão social e espacial, dentro do arcabouço legal existente. Para a autora, a formação de consórcios públicos enfrenta muitos obstáculos, exige tempo considerável e requer um profundo entendimento, tanto dos processos formais e informais, que levam ao consorciamento, quanto da Lei dos Consórcios Públicos.

Outro ponto importante que pode ser citado a favor da formação de consórcios públicos é a disseminação de políticas públicas e programas inovadores. Paulics, 2004 (apud Laczynsky, 2010), considera este processo na medida em que uma inovação é reproduzida por outras localidades ou quando um município se inspira em iniciativas desenvolvidas anteriormente em outros locais. Defende-se a teoria de que as inovações são construídas e disseminadas coletivamente, o que vai ao encontro da defesa de que os consórcios públicos podem ser bons arranjos para o desenvolvimento de uma região.

Um caso ilustrativo é a construção do Consórcio Integrado do Contestado CINCO, localizado na região do meio-oeste catarinense, que se constitui sob a 
forma de associação pública, com personalidade jurídica de direito público e natureza autárquica interfederativa. O CINCO tem por objetivos a união dos municípios da região do Contestado para a formulação de projetos estruturantes, que sustentem o desenvolvimento desta região, buscando formas de articulação intermunicipal com objetivo de integração, visando ao fortalecimento dos municípios, ao planejamento regional integrado, à captação de recursos financeiros para investimentos, à transferência de tecnologia, à ampliação de redes sociais, otimização, racionalização e transparência na aplicação dos recursos públicos, à regionalização de políticas públicas e à criação de parcerias institucionais sustentáveis (CINCO, 2010).

As informações do Ministério do Planejamento, Orçamento e Gestão (2010) sobre o Consórcio do ABC confirmam o sucesso desse tipo de consórcio, baseado nas premissas de que haja: (a) identidade regional com bases sociais e culturais; (b) construção de capital social pelas associações civis, sindicatos e imprensa da região; (c) liderança política; e (d) construção de arenas e instituições: fórum da cidadania, câmara regional e agência de desenvolvimento econômico.

Para esse grupo, os consórcios públicos se relacionam com a boa gestão no que tange: (a) ao aumento da capacidade de realização, a qual se resume em ampliação dos governos municipais em atendimento aos cidadãos e no alcance das políticas públicas por conta da disponibilidade maior de recursos e do apoio dos demais municípios; (b) na maior eficiência do uso dos recursos públicos, tratandose do caso dos consórcios cuja função central é o compartilhamento de recursos escassos, de máquinas de terraplanagem a unidades de saúde ou unidades de disposição final de resíduos sólidos; (c) na realização de ações inacessíveis a uma única prefeitura, um vez que o consórcio intermunicipal pode criar condições para que seja possível atingir resultados que não seriam possíveis a nenhuma prefeitura isoladamente, ou mesmo à soma dos esforços individuais de cada uma delas; (d) ao aumento do poder de diálogo, pressão e negociação dos municípios; (e) ao aumento da transparência das decisões públicas; ( $f$ ) ao aprendizado e à inovação; e (g) à sustentabilidade político-institucional, técnico-operacional e financeira (MINISTÉRIO DO PLANEJAMENTO ORÇAMENTO E GESTÃO, 2010).

Essa discussão é complementada por Rua (2009) que defende que as articulações locais/regionais são relevantes para a gestão pública e importantes na implementação de qualquer política pública. Assim, mesmo quando se trata apenas do nível local, para o sucesso da política, a autora destaca a importância dos vínculos entre diferentes organizações e agências públicas.

\section{Metodologia}

Para aumentar o nível de familiaridade com fenômenos relativamente desconhecidos e verificar a possibilidade de continuidade da investigação, Sampieri et al. (1991) argumentam que os estudos exploratórios são utilizados para avaliar questões reais, além de estabelecer prioridades para futuras investigações. Considerando os autores Cervo e Bervian (1996), Vieira (2002) e Malhotra (2001), 
foi realizado um estudo de caso, com sistematização de dados secundários e coleta de dados através de entrevistas semiestruturadas com os gestores, o que possibilitou aos entrevistados responder as questões com maior liberdade de expressão, ampliando a quantidade de informações sobre os temas abordados.

Com o objetivo de apresentar a evolução de alguns indicadores de caráter socioeconômico e institucional, tendo como base os dados da Fundação João Pinheiro - FJP, foram coletadas informações relacionadas à produção total dos municípios do consórcio, bem como aos aspectos de educação e saúde que compõem a vertente de caráter socioeconômico; já as informações referentes aos gastos e às receitas públicas, conselhos e incentivos formam a vertente de caráter institucional.

A maior parte dos resultados compreende o período de 2000 a 2010, seja comparando os extremos ou parte desse período, seja toda a série, tendo importância efetiva o indicativo de que a formação do consórcio, entre os anos de 2005 e 2006, pudesse ser um período de referência, captando alterações nos indicadores. Entende-se a complexidade desse tipo de análise e não se pretendeu aqui, com esta simples apresentação, confirmar se os períodos que sucederam a formação do CODAP apresentaram mudanças estatisticamente significativas, servindo mesmo como indicativo para este tipo de estudo. Além disso, com base nesses indicadores, a posterior coleta de dados, através de entrevistas direcionadas aos gestores públicos municipais, servirá também como sinalização de alterações na dinâmica socioeconômica e institucional do território em questão.

As entrevistas semiestruturadas realizadas no presente estudo com os gestores objetivam a confirmação ou não da hipótese de que a consolidação da estrutura institucional, o CODAP, contribui para o desenvolvimento da região em questão, considerando esse desenvolvimento como multidimensional, em que aspectos como investimentos e gastos públicos são importantes, mas que, além disso, outras dimensões como aumento do grau de confiança e cooperativismo, queda de barreiras partidárias, trabalhos coletivos etc. são tão relevantes para o desenvolvimento da região como aqueles primeiros aspectos citados.

O levantamento de informações foi realizado nas Prefeituras pertencentes ao CODAP, sendo guiado pelos argumentos expostos pelo Ministério do Planejamento, Orçamento e Gestão (2010): (a) capacidade de realização; (b) eficiência e uso dos recursos públicos; (c) ações coletivas; (d) poder de diálogo, pressão e negociação; (e) transparência das decisões públicas; f) aprendizado e Inovação e (g) sustentabilidade político-institucional, técnico-operacional e financeira. 


\section{Resultados e Discussão}

\subsection{A evolução dos indicadores econômicos e sociais ${ }^{1}$}

O primeiro bloco de indicadores compreende a evolução do PIB municipal, do PIB per capita, dos aspectos ligados à educação e saúde. A atenção está direcionada à percepção de existência de mudanças nas variáveis escolhidas por conta da formação do consórcio, entre os anos de 2005 e 2006, sendo oficialmente nesse último. Como já mencionado, as mudanças observadas servem como indicativo para estudos mais complexos, não apresentando significância estatística neste trabalho.

Em relação ao PIB, observando o comportamento das séries, de 2000 a 2008, tem-se que, a partir de 2004, o grupo passou a apresentar um aumento desse indicador, puxado pelos municípios de Congonhas, Ouro Branco, Conselheiro Lafaiete e São Brás do Suaçuí (Figura 2).

Figura 2. Produto Interno Bruto - PIB (R\$ mil dez de 2010 - Ano-base $2000=1)$.

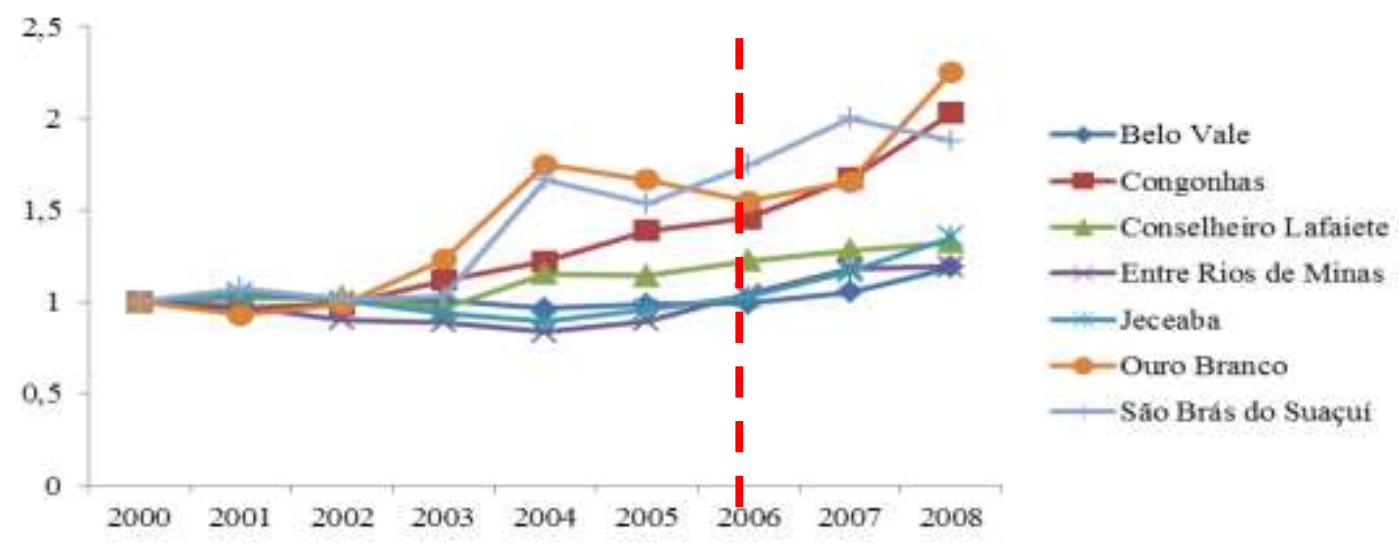

Nota: Linha tracejada na vertical representa o ano de criação oficial do consórcio.

Fonte: Elaboração própria.

Os resultados do PIB per capita mostraram uma evolução positiva de 2000 para 2010, para todos os municípios do CODAP (Tabela 1). Todos apresentaram uma taxa de crescimento acima de 50\%, com destaque para Belo Vale, com aumento de $83 \%$, aproximadamente. Os maiores valores absolutos, em 2010, são dos municípios de Ouro Branco, Conselheiro Lafaiete e Congonhas.

1 Os dados secundários foram extraídos da Fundação João Pinheiro - FJP. Disponível em http://www.fjp.gov.br/index.php/indicadores-sociais/-imrs-indice-mineiro-de-responsabilidadesocial 
Tabela 1.PIB per capita $(R \$)$

\begin{tabular}{lccc}
\hline Município & 2000 & 2010 & Var \% \\
\hline Belo Vale & 315,84 & 579,66 & 83,53 \\
Congonhas & 445,89 & 718,59 & 61,16 \\
Conselheiro Lafaiete & 519,62 & 810,12 & 55,91 \\
Entre Rios de Minas & 367,50 & 580,99 & 58,09 \\
Jeceaba & 295,38 & 499,19 & 69,00 \\
Ouro Branco & 579,77 & 885,55 & 52,74 \\
São Brás do Suaçuí & 340,07 & 558,75 & 64,30 \\
\hline
\end{tabular}

Fonte: Elaboração própria.

Referente à Educação (Tabela 2), a variável utilizada foi a Taxa de Analfabetismo, observando uma queda entre os anos 2000 e 2010, para todos os municípios, com destaque para Ouro Branco e São Brás do Suaçuí, com índice de $42 \%$, aproximadamente.

Tabela 2.Taxa de analfabetismo da população - 15 anos ou mais

\begin{tabular}{lccc}
\hline Município & 2000 & 2010 & Var \% \\
\hline Belo Vale & 11,56 & 8,57 & $-25,87$ \\
Congonhas & 6,89 & 4,49 & $-34,83$ \\
Conselheiro Lafaiete & 5,45 & 3,54 & $-35,05$ \\
Entre Rios de Minas & 11,62 & 8,06 & $-30,64$ \\
Jeceaba & 11,16 & 8,07 & $-27,69$ \\
Ouro Branco & 7,98 & 4,69 & $-41,23$ \\
São Brás do Suaçuí & 8,24 & 4,75 & $-42,35$ \\
\hline
\end{tabular}

Fonte: Elaboração própria.

Sobre a área da Saúde, a variável utilizada foi a extensão de um programa básico de assistência à população. Nesse caso, em termos percentuais, os dados da Figura 3 ilustram que, a partir de 2005, houve uma tendência de aumento geral dos níveis de atendimento. 
Figura 3. Proporção da população atendida pelo Programa de Saúde da Família -

PSF

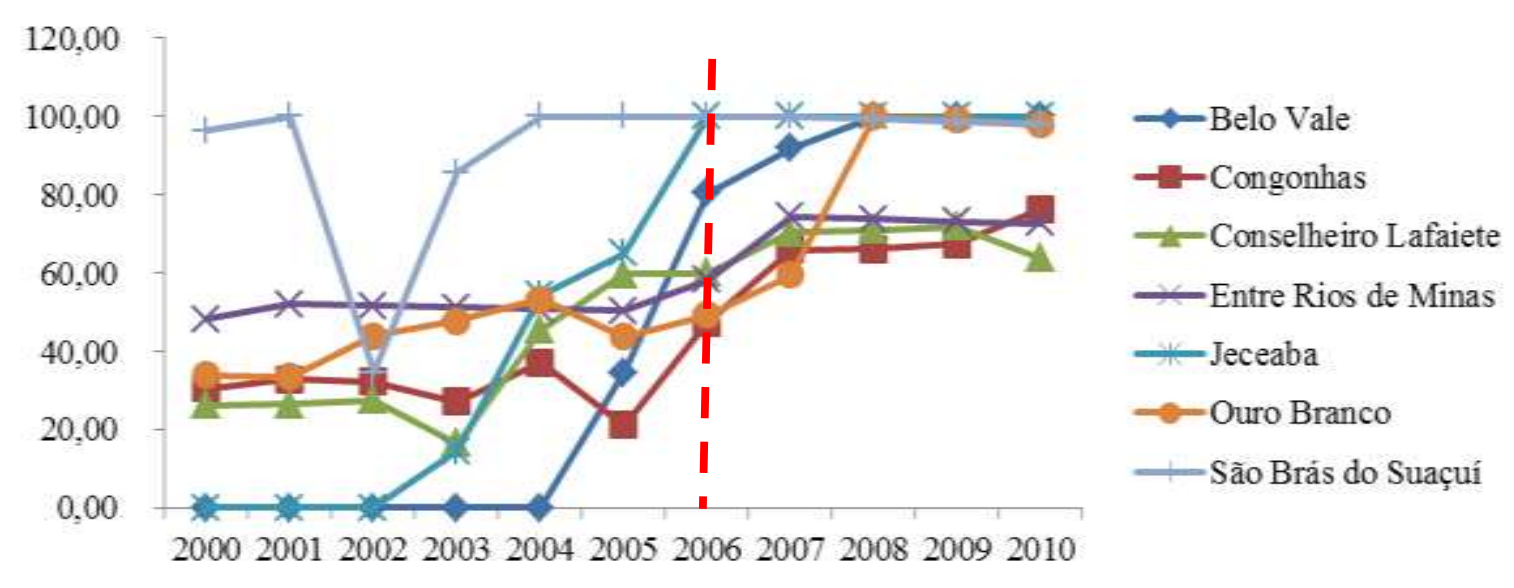

Fonte: Elaboração própria.

A variável apresentada na Tabela 3, assim como um conjunto de variáveis desse caráter, levanta hipóteses sobre os avanços institucionais, por conta da formaçãao do Consórcio, em cada município e na região, de forma geral. Questões sobre o fortalecimento institucional, com a formação de novos grupos e conselhos, devem ser discutidas. Até que ponto este consórcio público colabora com a formação de novos conselhos em cada município é uma questão posta, corroborando o fato de que essa aproximação formalmente estabelecida gera "transbordamentos" de informação nesse sentido. Os dados das Tabelas 3 e 4 indicam que alguns municípios, que não possuíam conselhos de habitação e de meio ambiente, passaram a possuir, após o período de formação de consórcio. Existe a possibilidade de essa transformação ter ocorrido através do planejamento regional que passou a ser construído de forma integrada, em que aspectos ligados à ocupação do solo e aspectos ambientais entraram nos eixos desses planos de gestão pública.

Tabela 3. Existência de Conselho Municipal de Habitação

\begin{tabular}{lccccccc}
\hline Município & 2000 & 2002 & 2003 & 2004 & 2008 & 2009 & 2010 \\
\hline Belo Vale & Não & Não & Não & Não & Não & Não & Não \\
Congonhas & Sim & Sim & Sim & Sim & Sim & Sim & Sim \\
Conselheiro Lafaiete & Sim & Sim & Sim & Sim & $\operatorname{Sim}$ & $\operatorname{Sim}$ & Sim \\
Entre Rios de Minas & Não & Não & Não & Não & Sim & Sim & Sim \\
Jeceaba & Não & Não & Não & Não & Não & Não & Não \\
Ouro Branco & Sim & Sim & Sim & Sim & Sim & Sim & Sim \\
São Brás do Suaçuí & Não & Não & Não & Não & Sim & Sim & Sim \\
\hline
\end{tabular}

Fonte: Elaboração própria. 
Tabela 4. Existência de Conselho de Meio Ambiente

\begin{tabular}{|c|c|c|c|c|c|c|c|}
\hline Município & 2000 & 2002 & 2003 & 2004 & 2008 & 2009 & 2010 \\
\hline Belo Vale & Sim & Sim & Sim & Sim & Sim & Sim & Sim \\
\hline Congonhas & Sim & Sim & $\operatorname{Sim}$ & $\operatorname{Sim}$ & $\operatorname{Sim}$ & $\operatorname{sim}$ & $\operatorname{Sim}$ \\
\hline Conselheiro Lafaiete & Sim & Sim & $\operatorname{sim}$ & Sim & $\operatorname{sim}$ & $\operatorname{Sim}$ & $\operatorname{Sim}$ \\
\hline Entre Rios de Minas & Sim & $\operatorname{Sim}$ & $\operatorname{Sim}$ & $\operatorname{Sim}$ & $\operatorname{Sim}$ & $\operatorname{Sim}$ & $\operatorname{Sim}$ \\
\hline Jeceaba & Não & Não & Não & Não & $\operatorname{Sim}$ & Sim & $\operatorname{Sim}$ \\
\hline Ouro Branco & Não & Não & Não & Não & $\operatorname{Sim}$ & $\operatorname{Sim}$ & $\operatorname{Sim}$ \\
\hline São Brás do Suaçuí & Sim & Sim & $\operatorname{sim}$ & Sim & Não & Não & Não \\
\hline
\end{tabular}

Fonte: Elaboração própria.

Outra variável de caráter institucional busca captar a existência de mecanismos de incentivo ao empreendedorismo, o que pode indicar um ambiente institucional formal favorável à geração de novos negócios e, consequentemente, ao desenvolvimento local. Do período que vai de 2005 a 2010, segundo dados apresentados na Tabela 5, os municípios de Congonhas, Jeceaba e Ouro Branco apresentaram uma mudança, no sentido positivo, a partir de 2008.

Tabela 5. Existência de mecanismos de incentivo à implantação de empreendimento

\begin{tabular}{lcccccc}
\hline Município & 2005 & 2006 & 2007 & 2008 & 2009 & 2010 \\
\hline Belo Vale & Não & Não & Não & Não & Não & Não \\
Congonhas & Não & Não & Não & Sim & Sim & Sim \\
Conselheiro Lafaiete & Sim & Sim & Sim & Sim & Sim & Sim \\
Entre Rios de Minas & Não & Não & Não & Não & Não & Não \\
Jeceaba & Não & Não & Não & Sim & Sim & Sim \\
Ouro Branco & Não & Não & Não & Sim & Sim & Sim \\
São Brás do Suaçuí & Não & Não & Não & Não & Não & Não \\
\hline
\end{tabular}

Fonte: Elaboração própria.

As demais variáveis relacionam-se diretamente com a administração pública municipal, captando mudanças nos gastos e nas receitas, principalmente ligados a fatores ambientais (ligados às atividades minerais e industriais), considerando que a formação desse consórcio fortaleceu este debate na região. Assim, os dados da Figura 4 indicam uma elevação generalizada dos gastos públicos per capita ao longo do período que vai de 2004 a 2010. 
Figura 4. Gasto per capita total ( $R \$$ de dez 2010/Hab - Ano-base: $2004=1)$

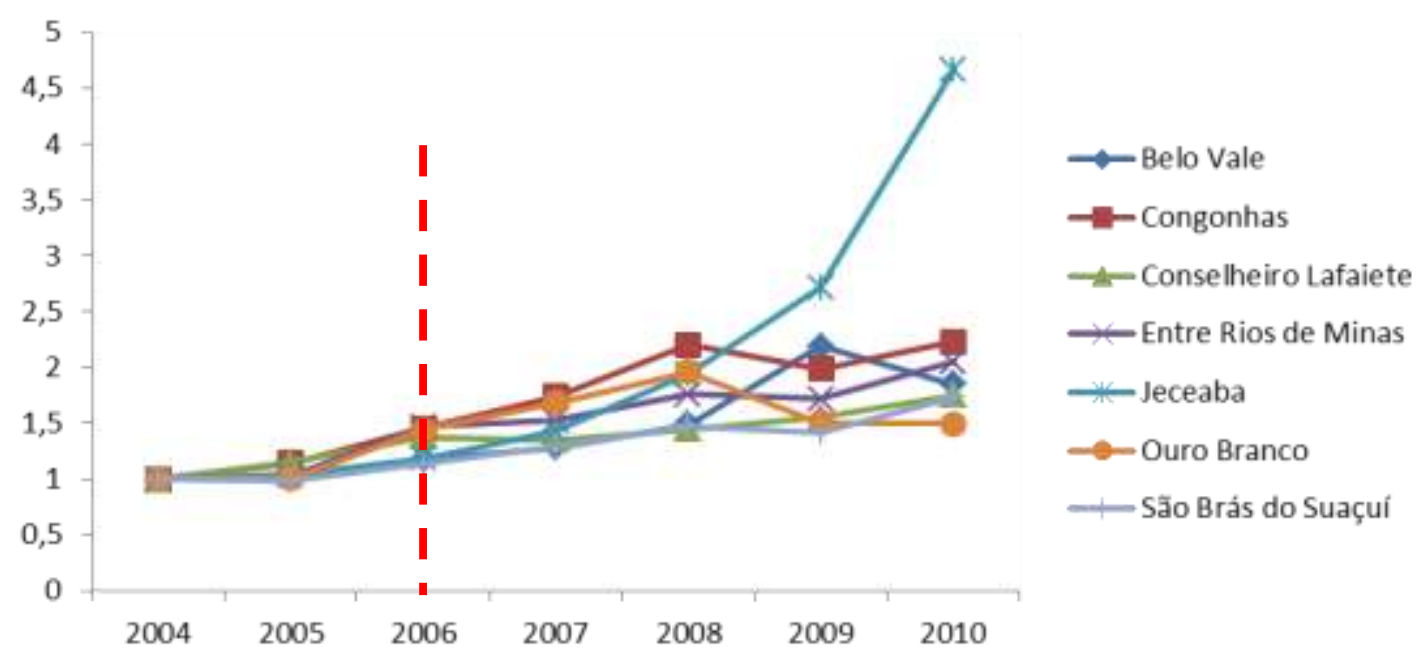

Fonte: Elaboração própria.

Já no que tange aos gastos per capita com o meio ambiente (tabela 6), pode-se notar que, para os municípios de Congonhas, C. Lafaiete e Ouro Branco, os valores aumentaram substancialmente a partir de 2006. De fato, a sinalização aqui é de que a formação do consórcio, somada ao desenvolvimento da atividade mineral na região, estimulou uma mudança institucional no sentido de elevar os gastos públicos em questões ambientais.

Tabela 6. Gasto per capita com meio ambiente. ( $R \$$ de dez 2010/hab)

\begin{tabular}{lccccccccc}
\hline Município & 2002 & 2003 & 2004 & 2005 & 2006 & 2007 & 2008 & 2009 & 2010 \\
\hline Belo Vale & - & - & - & - & - & - & - & - & - \\
Congonhas & 0,78 & 1,54 & 1,15 & 4,91 & 13,46 & 13,44 & 15,39 & 8,88 & 58,69 \\
Conselheiro Lafaiete & 0,06 & 0,75 & 0,90 & 1,10 & 23,76 & 20,02 & 32,52 & 28,93 & 31,35 \\
Entre Rios de Minas & 1,14 & 0,84 & 0,36 & 0,44 & 1,04 & 0,75 & 0,92 & 0,86 & 0,73 \\
Jeceaba & - & - & - & - & - & - & - & - & 1,12 \\
Ouro Branco & 6,11 & 5,40 & 7,28 & 1,80 & 32,78 & 14,36 & 29,96 & 12,27 & 6,89 \\
São Brás do Suaçuí & - & 0,09 & 3,48 & 2,32 & 3,00 & 0,32 & 0,48 & 0,67 & 2,48
\end{tabular}

Fonte: Elaboração própria.

As duas últimas variáveis escolhidas referem-se à receita dos municípios e também sinalizam que mudanças institucionais podem ter interferido na evolução dessas receitas. Assim, conforme os dados da Figura 5, tendo o ano de 2001 como base (igual a 1), o comportamento das séries, para os 5 municípios apresentados, indica que, a partir de 2007/2008, os valores captados do ICMS ecológico sofreram aumento. Vale destacar que os municípios de C. Lafaiete, bem como Belo Vale e São Brás do Suaçuí (retirados da Figura 5 por apresentarem dados somente em 2010), apresentaram valores muito elevados nesse último ano, indicando uma mudança institucional favorável ao recolhimento desse imposto. 
Figura 5. ICMS recebido pelo critério ecológico da Lei Hobin Hood (2001=1).

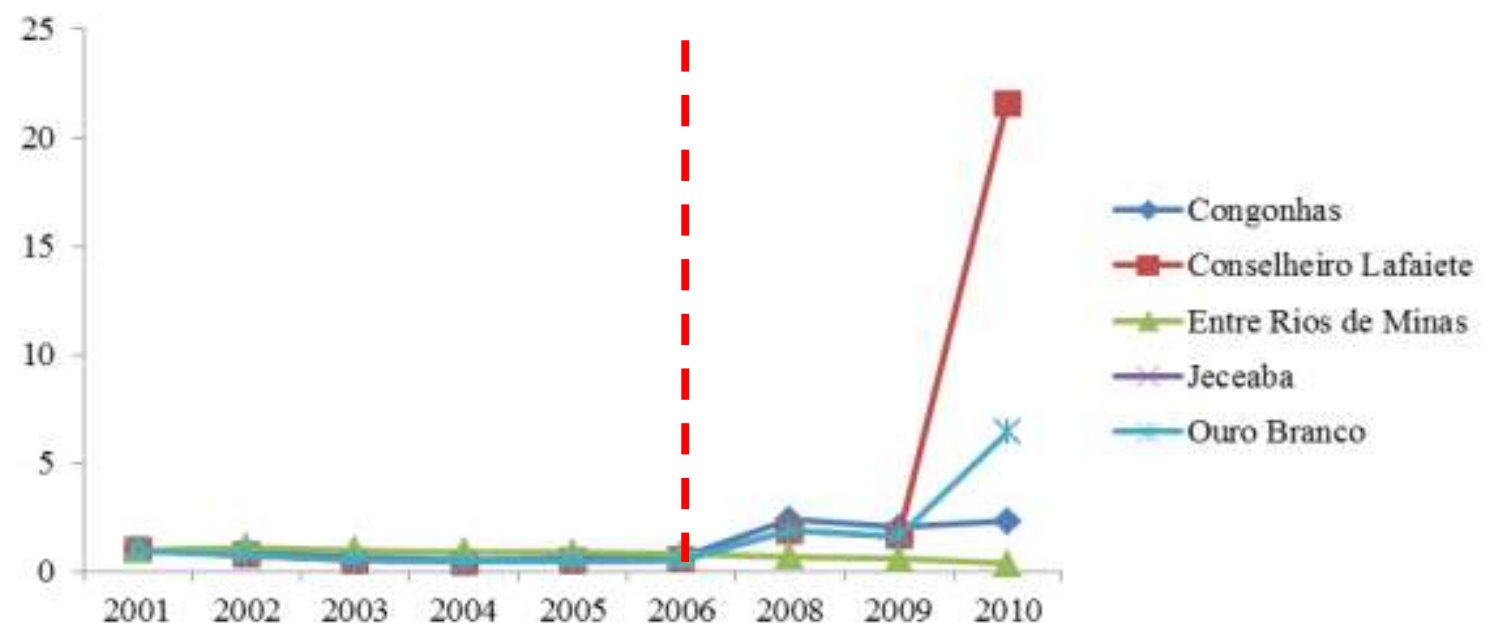

Fonte: Elaboração própria.

Por fim, uma variável bem relacionada à questão institucional, que pode captar a possível relação entre receita pública municipal e arranjo institucional é a razão entre as transferências recebidas pelo governo na forma de convênios e a Receita Corrente Líquida - RCL. A sinalização principal é o fato de aumentar as transferências na forma de convênios em relação à receita pública municipal, neste caso, a RCL. Os dados indicam que há uma concentração de valores relativamente maiores a partir de 2006 esta razão aumentou, com exceção para Ouro Branco, (Tabela 8). Possivelmente a nova lógica organizacional da gestão pública, integrada através do consórcio, foi responsável pelo aumento desse nível de transferências decorrente justamente de convênios, principalmente devido ao aumento das transferências que acontecem justamente por conta da existência de um consórcio.

Tabela 8. Razão entre o montante de transferências recebidas pela administração na forma de convênios e sua RCL (\%)

\begin{tabular}{lcccccccccc}
\hline \multicolumn{1}{c}{ Município } & 2000 & 2002 & 2003 & 2004 & 2005 & 2006 & 2007 & 2008 & 2009 & 2010 \\
\hline Belo Vale & 0,95 & 9,55 & 6,25 & 3,96 & 1,76 & 7,29 & 0,88 & 5,87 & 19,14 & 5,66 \\
Congonhas & 1,23 & 0,72 & 1,26 & 2,34 & 0,86 & 0,94 & 1,63 & 4,16 & 1,43 & 1,47 \\
Conselheiro Lafaiete & 1,82 & 0,48 & & 0,91 & 0,09 & 1,39 & 0,96 & 4,55 & 0,45 & 10,70 \\
Entre Rios de Minas & 6,31 & 4,40 & 5,08 & 2,80 & 5,41 & 4,59 & 7,85 & 14,60 & 3,17 & 11,19 \\
Jeceaba & 3,07 & 5,54 & 3,84 & 18,15 & 1,89 & 5,62 & 1,03 & 6,29 & 0,16 & 0,29 \\
Ouro Branco & 24,06 & 16,17 & 1,99 & 3,03 & 1,64 & 0,61 & 0,51 & 3,15 & 0,35 & 0,86 \\
São Brás do Suaçuí & 4,02 & 7,71 & 0,55 & 4,66 & & 4,46 & 4,99 & 14,41 & 0,64 & 5,27 \\
\hline
\end{tabular}

Fonte: Elaboração própria.

De forma complementar a essa análise de variáveis, a coleta de dados, diretamente da gestão pública municipal, no que se refere ao novo ambiente 
institucional criado a partir da formação do CODAP, vai fortalecer o entendimento da evolução desses indicadores supracitados, além de contribuir para a discussão que envolve a concepção de consórcios públicos e os resultados, em termos institucionais, para o desenvolvimento da região em que se inserem.

\subsection{A percepção dos gestores públicos}

O CODAP é formado por sete municípios. Com exceção do município de Belo Vale, os demais seis participaram com informações e opiniões sobre a implantação do CODAP: Congonhas, Conselheiro Lafaiete, Jeceaba, Ouro Branco, São Brás do Suaçuí e Entre Rios de Minas.

Os dados mostraram que as seis Prefeituras conhecem a legislação recente sobre consórcios públicos. Destaca-se que as seis prefeituras confirmaram que já participaram de outro tipo de consórcio, como, por exemplo, consórcio na área da saúde, como citado pelas Prefeituras de São Brás, Entre Rios de Minas e Jeceaba; ou então outros tipos de associação, como a Associação Mineira dos Municípios AMM - e a Associação dos Municípios da Microrregião do Alto Paraopeba AMALPA, citadas no questionário de Entre Rios. O Prefeito de Congonhas ainda acrescentou o Consórcio de Bacia Hidrográfica - CIBAPAR e o Consórcio de Aterro Sanitário - ECOTRES.

Outro dado importante foi sobre o relacionamento dos prefeitos antes e após a formação do consórcio. Três responderam que essa relação tinha nota média e passou a ter nota boa; outros dois disseram que a relação já era boa e continuou do mesmo jeito após consórcio; e um deles assumiu que a relação era ruim e passou a ser boa. Isso indica que essas ferramentas institucionais (criação de consórcios públicos) podem colaborar para o fortalecimento do cooperativismo entre gestores públicos de uma mesma região.

Por fim, algumas Prefeituras confirmaram que a economia da região tornou-se mais dinâmica e apenas uma prefeitura não respondeu a questão, argumentando o grau de complexidade que esta abrange, não sendo o CODAP um balizador único para entendimento da economia de cada município. A Prefeitura de São Brás assume que houve grande expansão e desenvolvimento integrado; já a Prefeitura de Entre Rios confirma que "a economia da região aqueceu-se principalmente após a implantação do Distrito Industrial, pela Vallourec \& Sumitomo Tubos do Brasil - VSB". Além disso, respondeu também que nos últimos anos a economia da região modificou-se por conta da dinâmica de outras empresas, como a CSN, Gerdau, Vale do Rio Doce, dentre outras; a Prefeitura de Conselheiro Lafaiete também assume que a economia está em franca expansão, argumentando que o CODAP atua como suporte técnico para que os municípios possam captar e utilizar os recursos de forma mais eficiente. A Prefeitura de Congonhas completa "A economia da região saiu de uma situação de grave estagnação e decadência para uma situação de crescimento acelerado, impondo aos municípios, inclusive, desafios até então inéditos". A avaliação das 
Prefeituras é de que a região saiu do anonimato para uma posição de destaque na economia mineira.

A avaliação do consórcio sob a ótica dos gestores públicos municipais, considerando os itens relacionados pelo Ministério do Planejamento Orçamento e Gestão (2010), revela que, sobre a "Capacidade de realização", as seis prefeituras confirmaram que houve aumento do número de cidadãos beneficiados depois da instalação do CODAP, principalmente em áreas como licitações, compras coletivas, resíduos sólidos, como citado pela Prefeitura de Jeceaba: "os programas de gestão; a fazenda modelo; o plano de desenvolvimento sustentável regional; todos eles propiciaram ganhos para muitas pessoas". Outras prefeituras ainda acrescentaram as áreas de educação e qualificação profissional.

Efetivamente sobre o número de recursos pós-CODAP, cinco Prefeituras informaram que houve aumento, o que colabora com a capacidade de realização desse arranjo, como destacou a Prefeitura de Entre Rios, com referência a articulação para o Programa de Modernização da Administração Tributária e da Gestão dos Setores Sociais Básicos - PMAT, do Banco Nacional de Desenvolvimento Econômico e Social - BNDES.

Sobre a "Eficiência e uso dos recursos públicos", no que tange ao uso de recursos escassos, de forma compartilhada, nenhuma Prefeitura declarou que esse uso foi mais eficiente com o uso das máquinas de terraplanagem. Outro disse que os recursos foram mais escassos foi em unidades de saúde; e as Prefeituras de São Brás e Ouro Branco apontaram as unidades para depósito de resíduos sólidos. Houve também respostas ligadas à Defesa Civil e ao Plano de Desenvolvimento Integrado ${ }^{2}$. Os outros não responderam a questão.

Já sobre "Ações coletivas", deve-se considerar a importância desse ponto, na medida em que aborda o caráter coletivo e indispensável para algumas ações que o consórcio assume. Nesse sentido, as Prefeituras indicaram algumas ações que passaram a ser possíveis de execução após o CODAP. A Prefeitura de São Brás apontou ações na área da saúde e da agricultura familiar; a Prefeitura de Jeceaba indicou compras coletivas e acesso a outras esferas governamentais; a Prefeitura de Entre Rios apresentou os programas de Defesa Civil, de Fiscalização Tributária Conjunta, de Georreferenciamento, e de Compras Coletivas. A Prefeitura de Ouro Branco apresentou ainda o Aterro Sanitário e confirmou as questões já colocadas até aqui. Congonhas, por sua vez, cita os acordos de cooperação com a UNESCO, EMBRAPA e Banco do Brasil.

Sobre "Poder de diálogo, pressão e negociação", ou seja, sobre os aspectos relacionados ao fluxo de informação e ao aumento de poder de negociação, todas as prefeituras disseram que houve aumento nesse sentido. Como ressalta a Prefeitura de São Brás: "Ações planejadas no nível regional, com pauta de reunióes e encaminhamentos coletivos por parte dos Prefeitos e Secretários"; a Prefeitura de Jeceaba deu peso para as constantes conferências regionais e

2 O Plano de Desenvolvimento Integrado do CODAP pode ser compreendido em http://www.planejamento.mg.gov.br/governo/choque/premio_excelencia/5_premio/3_lugarcategoria_1-219.pdf 
seminários, que permitiram "uma interlocução constante entre secretarias, população, etc"; a Prefeitura de Entre Rios citou o pacto entre o Poder Executivo, além dos processos da Agenda 21 Local, em que o grupo busca o desenvolvimento sustentável da região; por fim, Ouro Branco também dá destaque ao aumento de reuniões como incremento à comunicação entre os envolvidos.

Para "Transparência das decisões públicas", todos responderam que as informações sobre as políticas locais ficaram mais disponíveis depois do CODAP. A Prefeitura de São Brás argumentou que houve mais troca de informações com órgãos estaduais e federais, além da iniciativa privada. Entre Rios disse que a instalação da Agenda 21 Local aumentou o número de reuniões técnicas, além de citar a divulgação das ações em sites e revistas especializadas, dentre outros meios.

Por fim, para os tópicos "Aprendizado e Inovação" e "Sustentabilidade político-institucional, técnico-operacional e financeira", as Prefeituras destacaram que a área mais beneficiada pelo consórcio foi a Política, seguida das áreas sobre economia e meio ambiente. Para complementar, todas as prefeituras confirmaram que existe um conhecimento sendo compartilhado após a instalação do CODAP e que esse está relacionado às questões ambientais, de gestão pública, fiscais, dentre outras de menor destaque, como sociais e agropecuárias. Já a Prefeitura de Entre Rios destaca como fatores prioritários advindos da instalação do CODAP: "principalmente os conhecimentos voltados à necessidade de melhor dinamização da máquina pública, com eficiência nos gastos e melhoria das arrecadações".

\section{Considerações Finais}

O Consórcio Público para o Desenvolvimento do Alto Paraopeba - CODAP foi o primeiro modelo de consórcio público em Minas Gerais, sob o regime da Lei Federal $n^{\circ} 11.107$ e integra sete municípios. O presente estudo teve por objetivo apresentar e confirmar argumentos favoráveis à implantação desse tipo de política pública como modelo de arranjo institucional regional, envolvendo, neste momento, apenas a ótica dos gestores públicos (Prefeituras). Para tanto, foram analisados indicadores em três níveis - econômico social e institucional -, e ainda foi aplicado um questionário semiestruturado que se orientou por pontos referentes aos trabalhos do Ministério do Planejamento, Orçamento e Gestão.

Esse tipo de estudo vai ao encontro dos debates sobre o papel das instituições no desenvolvimento de regiões. Pensar como um consórcio entre municípios pode ser uma boa ferramenta de gestão é pensar também como esse tipo de ambiente institucional pode favorecer ou facilitar a gestão pública e, consequentemente, ampliar e melhorar as políticas públicas municipais.

O debate acerca das variáveis que realmente são significantes para o desenvolvimento foi se acirrando na medida em que foram incorporadas novas dimensões e questões, como instituições, colocadas como fundamentais além daquelas relacionadas diretamente com produção e consumo.

Transportando para o presente caso, o entendimento das redes sociais e da lógica institucional presente em uma região (seja ela em forma de leis, regras 
formais, decretos ou na forma de confiança e de cooperação entre os diferentes agentes dessa sociedade) é determinante para o desenvolvimento mais ampliado dos municípios envolvidos, entendendo-se este desenvolvimento sob os aspectos sociais, ambientais, econômicos, humanos, políticos, dentre outros. Grandes contribuições teóricas foram apresentadas e, com a abordagem da Nova Economia Institucional - NEl, por exemplo, estes estudos que envolvem ação coletiva, regimes, redes de confiança e uso de recursos comuns, se tornaram básicos para pesquisadores e planejadores interessados pelo assunto.

Os resultados indicaram uma boa avaliação por parte deste grupo. Os aspectos relacionados à capacidade de realização e de eficiência do uso dos recursos públicos apresentaram-se favoráveis para todos. O ponto referente à realização de ações inacessíveis a uma única Prefeitura também foi muito interessante, tendo exemplos claros da importância que o CODAP assumiu nesse sentido; além disso, o aumento do poder de diálogo e o aumento da transparência das decisões públicas também foram expostos pela maioria. Percebe-se claramente que o CODAP é um modelo que surgiu em um ambiente favorável cooperativo, seja por afinidades políticas, seja por objetivos comuns, no que tange ao desenvolvimento de uma região. Sendo assim, sua evolução tem sido positiva e questões, que antes fugiam das pautas das políticas municipais entraram no eixo dos programas para o desenvolvimento, desde a formulação de um planejamento conjunto, até programas ambientais cuja sustentabilidade tornou-se questão fundamental em uma região com atividades minerais e industriais.

\section{REFERÊNCIAS}

AMIN, Ash. An institutionalist perspective on regional economic development. Department of Geography UCL, London. 1998. Disponível em: <http://foromundialadel.org/experiencias/doc/ash\%20aminregional\%20economic.pdf > . Acesso em agosto de 2011.

CERVO, A.L. e BeRVIAN, P. A. Metodologia Científica. 5a Edição. São Paulo: Ed. Prentice Hall, 2002.

CINCO. Contrato do Consórcio Integrado do Contestado. Disponível em: $<$ http://www.cinco.sc.gov.br/cms/upload-images/documentos/57_1.pdf. (S/D)>. Acesso em Agosto de 2011.

ESTEVA, Gustavo. Desenvolvimento. In; SACHS, W. Dicionário de Desenvolvimento: guia para o conhecimento do poder. Petrópolis: Vozes, 2000.

FJP - Fundação João Pinheiro. Índice Mineiro de Responsabilidade Social. Disponível em: <http://www.fjp.gov.br/index.php/indicadores-sociais/-imrsindice-mineiro-de-responsabilidade-social > Acesso em março de 2012.

GRANOVETER, Mark. Economic Action and Social Structure: the problem of embeddedness. AJS, number 3, 1985. Disponível em: 
<http://glennschool.osu.edu/faculty/brown/home/Org\% 20Theory/Readings/Gr anovetter1985.pdf>

LACZYNSKI, Patrícia. Formação de consórcios públicos em regiões metropolitanas: o caso do projeto Novos Consórcios Públicos para Governança Metropolitana. III Congresso Consad de Gestão Pública 2010.. Disponível em: <http://www.repositorio.seap.pr.gov.br>. Acesso em Julho de 2011.

MALHOTRA, Naresh K. Pesquisa de Marketing: uma orientação aplicada. $3^{a}$ ed. Porto Alegre: Bookman, 2001.

MELlO, F. F; FERREIRA, G. G., LEITE, I. M. Projeto "Planejamento $e$ Desenvolvimento Regional do Alto Paraopeba". Disponível em <http://www.planejamento.mg.gov.br/governo/choque/premio_excelencia/5_pr emio/3_lugar-categoria_1-219.pdf >. Acesso em setembro 2011.

MINAYO, Maria Cecília S. Pesquisa Social: teoria, método e criatividade. 12a . ed. Rio de Janeiro: Vozes, 1999.

MINISTÉRIO DO PLANEJAMENTO ORÇAMENTO E GESTÃO. Projeto Brasil Municípios. O Futuro dos Consórcios Públicos e a Agenda da Boa Gestão Municipal. Encontro Estadual de Consórcios Públicos: Avanços e Oportunidades Fortaleza, 2011. Disponível em <http://www.consorciopublico.ce.gov.br, 2010>. Acesso em Julho de 2011.

NORTH, Doulglas. Institutions, Institutional Change and Economic Performance. Cambridge University Press - Cambridge. 1990.

PEYREFITTE, Alain. Os milagres na economia. Bauru: EDUSC, 2000.

PREFEITURA DE CONGONHAS. Minuta do Termo de Cooperação Técnica. Disponível em <http://www.congonhas.mg.gov.br. (S/D)>. Acesso em julho de 2011.

QUARESMA, Valdete B. e S. J. Aprendendo a entrevistar: como fazer entrevistas em Ciências Sociais. Revista Eletrônica dos Pós-Graduandos em Sociologia Política da UFSC. Vol. 2 no 1 (3), p. 68-80, 2005.

RUA, Maria das Graças. Políticas públicas. Florianópolis: Departamento de Ciências da Administração / UFSC; [Brasília]: CAPES : UAB, 2009.

RUIZ, Ricardo Machado; BARBIERI, Alisson. Plano de Desenvolvimento Regional para o Alto Paraopeba. CEDEPLAR/UFMG. Acesso em maio de 2011. Disponível em: $\quad<$ http://www2.almg.gov.br/opencms/export/sites /default/hotsites/2010/debate_paraopeba/docs/ricardo_ruiz.pdf

SAMPIERI, R. H.; COLLADO, C. F.; LUCIO, P. B. Metodología de la investigación. México: McGraw-Hill, 1991. 
SCHMITZ, H. Collective Eficiency and Increasing Returns. 1997. Disponível em <http://cje.oxfordjournals.org/content/23/4s/465.abstract>. Acesso em Setembro 2011.

SEDRU - Secretaria Estadual de Desenvolvimento Regional e Política Urbana. Consórcios. Acesso em Julho de 2011. Disponível em: <http://www.urbano.mg.gov.br/municipios/consorcios, 2011>.

SOARES, Weber. Confiança, redes sociais, inovação e desenvolvimento local. Belo Horizonte: Proex. UFMG. 2009.

STORPER, Michael. Regional Economies as Relational Assets. In: LEE, Roger \& Wills, Jane (eds.) Geographies of Economies. London: Arnold, 1997. Disponível em $<$ http://time.dufe.edu.cn/spti/article/storper/RegEcRelAssets.pdf >

VIEIRA, Valter Afonso. As tipologias, variações e características da pesquisa de Marketing. Revista da FAE, Curitiba, v.5, n.1, p.61-70, jan./abr, 2002.

Submetido em $17 / 10 / 2013$

Aprovado em 05/05/2015

\section{Sobre os autores}

Hilton Manoel Dias Ribeiro

Professor do Departamento de Economia da Universidade Federal de Juiz de Fora - UFJF/Campus GV - MG - Brasil.

Endereço: Avenida Doutor Raimundo Monteiro Rezende, Centro. 35010177 - Governador Valadares, MG - Brasil

E-mail: hilton.manoel@ufjf.edu.br

\section{Dalva Maria Righi Dotto}

Professora Adjunta da Universidade Federal de Santa Maria - UFSM. Doutora em Desenvolvimento Regional.

Endereço: Rua Francisco Guerino, Centro. 97195970 - Silveira Martins, RS - Brasil

E-mail: dalvadotto@gmail.com 